\title{
Genome-wide association studies for growth traits in broilers
}

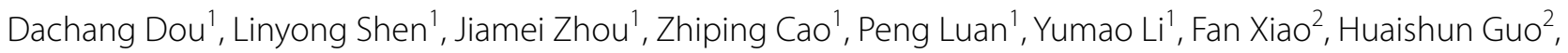 \\ Hui Li ${ }^{1}$ and Hui Zhang ${ }^{1 *}$
}

\begin{abstract}
Background: The identification of markers and genes for growth traits may not only benefit for marker assist selection /genomic selection but also provide important information for understanding the genetic foundation of growth traits in broilers.

Results: In the current study, we estimated the genetic parameters of eight growth traits in broilers and carried out the genome-wide association studies for these growth traits. A total of 113 QTNs discovered by multiple methods together, and some genes, including ACTA1, IGF2BP1, TAPT1, LDB2, PRKCA, TGFBR2, GLI3, SLC16A7, INHBA, BAMBI, APCDD1, GPR39, and GATA4, were identified as important candidate genes for rapid growth in broilers.
\end{abstract}

Conclusions: The results of this study will provide important information for understanding the genetic foundation of growth traits in broilers.

Keywords: Broiler, Growth trait, Body weight, GWAS, Heritability

\section{Background}

The chicken (Gallus gallus), as an important model animal, could fulfill the evolutionary gap among mammals and other vertebrates. Some substantial advances have been made to improve the growth rate in chicken for the past more than 60 years under artificial selection and rapid growth in broilers will continue to be the most important economic trait in breeding programs. Growth traits in chicken often have high heritability and phenotypic selection may obtain good selection progress. However, the identification of markers and genes for growth traits may not only benefit for marker assist selection (MAS)/genomic selection (GS) but also provide

\footnotetext{
*Correspondence: huizhang@neau.edu.cn

${ }^{1}$ Key Laboratory of Chicken Genetics and Breeding, Ministry

of Agriculture and Rural Affairs; Key Laboratory of Animal Genetics, Breeding and Reproduction, Education Department of Heilongjiang

Province; College of Animal Science and Technology, Northeast

Agricultural University, Harbin 150030, P. R. China

Full list of author information is available at the end of the article
}

important information for understanding the genetic basis of growth traits in broilers.

Genome-wide association studies (GWAS) is a technology to identify loci significantly associated with traits of interested by using single nucleotide polymorphisms (SNP) chips or sequencing technology which screen hundreds of thousands or even millions of SNPs or some other kinds of variants in the genomes. This approach is first used in human to detect causal mutations for disease and until now many loci for diseases, especially for many kinds of cancers, are identified [1,2]. GWAS is also implemented in domestic animals to identify the genetic factors associated with economically important traits [35]. Thanks to the advantage of SNP arrays and genomic resequencing methods for animals, it is relatively easy to genotype a wide array of individuals. As a result, many GWAS have been carried out in the past few years. In chickens, a number of markers or genes important for growth, meat quality, and fertility traits, were identified in different populations by using GWAS [6-9]. 
Our team constructed the Northeast Agricultural University broiler lines divergently selected for abdominal fat content (NEAUHLF) since 1996 [10]. Plasma VLDL concentration of individual and its fullsibs' abdominal fat percentage (AFP) were used as criteria. Using this population, we carried out the GWAS analysis for plasma VLDL concentration and for fertility traits [11, 12]. For growth rate, an important quantitative trait in broilers, it is important to identify markers or genes that could be used in breeding program to improve it quickly. Therefore, in the current study, GWAS was used to identify important genes for growth traits in NEAUHLF. The results of this study will provide important information for understanding the genetic background of growth traits in broilers.

\section{Results}

Genetic parameter estimation of growth traits in broilers The descriptive information of the eight growth traits, including BW1, BW3, BW5, BW7, ChWi, KeL, MeC and MeL, was shown in Table 1 . The results indicated that BW7 used in the current study was about $2.4 \mathrm{~kg}$. The heritability of these eight growth traits were estimated and we found that six of these traits, including BW1, BW3, BW5, BW7, ChWi and MeC, have high heritability $\left(h^{2}>0.3\right)$ (Fig. 1). However, KeL $\left(h^{2}=0.16\right)$ and MeL $\left(h^{2}=0.18\right)$ have a little low heritability. The genetic and phenotypic correlation between body weight at different weeks of age were high $(r>0.3)$ (Fig. 1). Overall, the genetic correlation between every two of the eight growth traits were moderate or high except several low ones, such as the genetic correlation between ChWi and $\mathrm{MeC}$, and between $\mathrm{ChWi}$ and $\mathrm{MeL}$ were-0.02 and -0.09 , respectively (Fig. 1 ).

\section{GWAS results for growth traits in broilers}

The six multi-locus GWAS methods in the mrMLM v4.0.2 package, were used to carry out the GWAS analysis for the eight growth traits of 475 male birds from the 11th generation of NEAUHLF (Fig. 2). We identified 285 quantitative trait nucleotides (QTNs) with significant effects on eight of the growth traits, including BW1, BW3, BW5, BW7, ChWi, KeL, MeC and MeL, based on a logarithm of odds (LOD) threshold of $\geq 3$. Of these QTNs, 113 ones were discovered by multiple methods together (at least two methods) (Table S1). These significant QTNs for growth traits were distributed on chromosomes 1, 2, 3, 4, 6, 7, 8, 12, 13, 15, 19, 20, 23, and 26 (Fig. 2).

\section{Difference of phenotypes between different alleles}

A total of 26 QTNs with significant effects on growth traits were detected by at least four multi-locus GWAS methods, including 3, 3, 3 and 1 significant QTNs for body weight at 1, 3, 5 and 7 weeks of age, respectively, and 6 QTNs for ChWi, 4 QTNs for KeL, 4 QTNs for MeC and 2 QTNs for MeL. The difference of growth traits between two alleles of the QTNs with significant effects were calculated. The results indicated that birds with different alleles have significantly different $(P<0.05)$ phenotypes (BW1, BW3, BW5, BW7, ChWi, KeL, MeC and MeL) for all 26 QTNs (Fig. 3).

\section{Candidate genes for growth traits in broilers}

A total of 184 chicken Refgenes were harbored in $1 \mathrm{Mb}$ regions surrounding the 113 QTNs with significant effects on growth traits by multiple methods together (Table S1). Using these 184 genes, the GO and KEGG analyses were carried out. The results indicated that twenty-seven GO terms reached the statistically significant level $(P<0.05)$ (Fig. 4). These GO terms were mainly involved in cell differentiation, regulation of cellular macromolecule biosynthetic process, postsynaptic membrane, RNA polymerase II-specific and etc. Only three KEGG pathways reached the significant level according to the KEGG pathway analyses (Fig. 4). The papers about these 184 genes were found and some genes, including Acetyl Coenzyme A Acetyltransferase 1 (ACTA1),

Table 1 Descriptive information of growth traits in broilers

\begin{tabular}{|c|c|c|c|c|c|c|c|}
\hline Growth traits & Mean & $\begin{array}{l}\text { Standard } \\
\text { deviation }\end{array}$ & Max & Min & C.V. (\%) & Phenotypic variance & Genetic variance \\
\hline BW1 (g) & 122.00 & 12.33 & 174.60 & 70.10 & 10.11 & 157.64 & 86.12 \\
\hline BW3 (g) & 615.22 & 65.90 & 797.00 & 332.00 & 10.71 & 4527.37 & 2564.09 \\
\hline BW5 (g) & 1491.19 & 142.38 & 1815.00 & 940.00 & 9.55 & $20,517.80$ & 7370.30 \\
\hline BW7 (g) & 2400.97 & 221.41 & 3020.00 & 1755.00 & 9.22 & $49,804.20$ & $16,163.70$ \\
\hline ChWi (cm) & 9.23 & 0.74 & 11.84 & 7.21 & 8.02 & 0.48 & 0.16 \\
\hline $\mathrm{KeL}(\mathrm{cm})$ & 13.75 & 0.73 & 18.84 & 9.96 & 5.31 & 0.45 & 0.07 \\
\hline $\mathrm{MeC}(\mathrm{cm})$ & 5.10 & 0.39 & 6.35 & 4.35 & 7.65 & 0.06 & 0.03 \\
\hline MeL (cm) & 9.25 & 0.46 & 10.54 & 7.75 & 4.97 & 0.14 & 0.03 \\
\hline
\end{tabular}




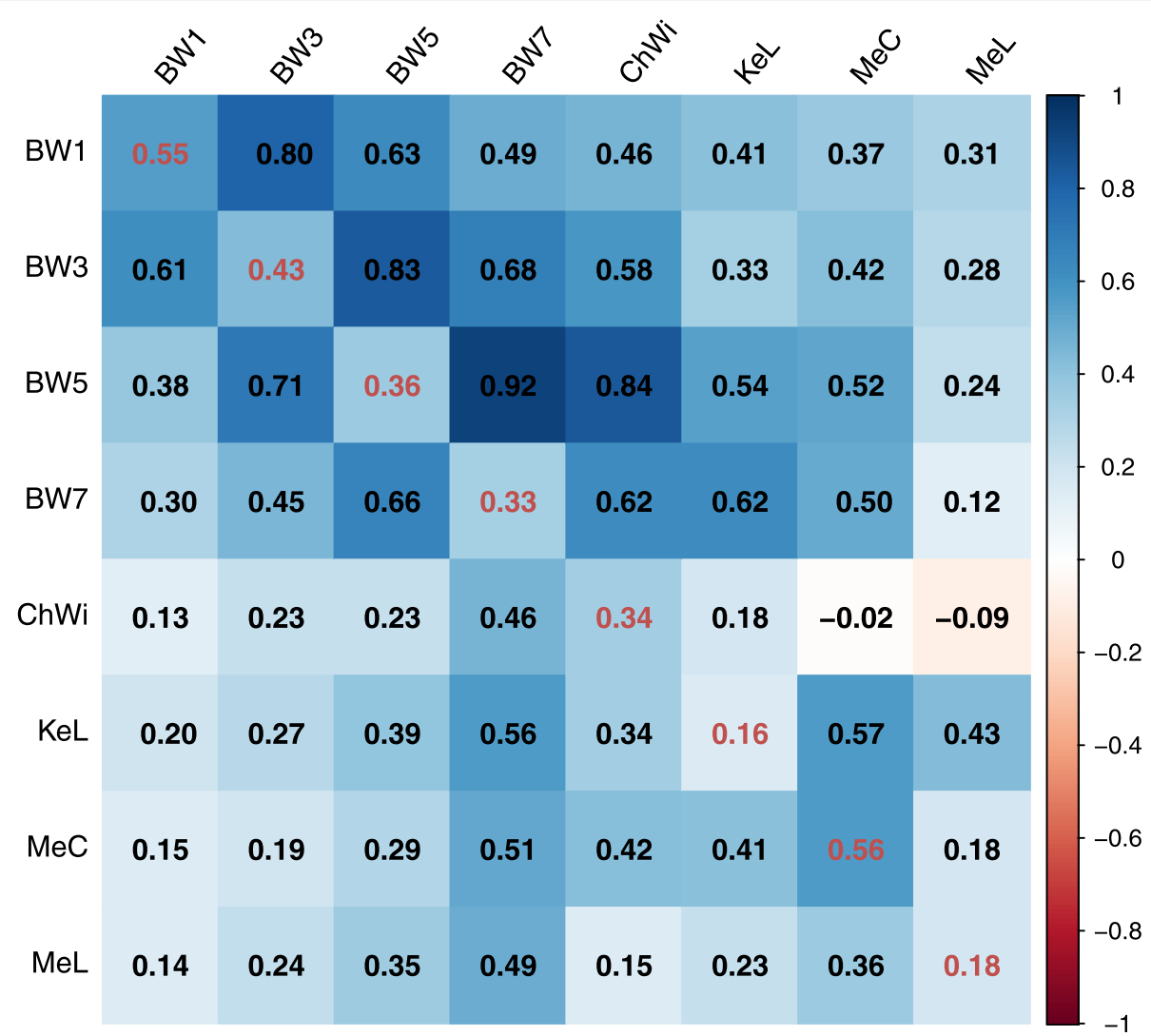

Fig. 1 Genetic parameters of the eight growth traits in broilers. Heritability was on the diagonal. Above the diagonal were the genetic correlations between every two traits and below the diagonal were the phenotypic correlations

Insulin-Like Growth Factor 2 MRNA Binding Protein 1 (IGF2BP1), Transmembrane Anterior-Posterior Transformation 1 (TAPT1), LIM Domain Binding 2 (LDB2), Protein Kinase C Alpha (PRKCA), Transforming Growth Factor Beta Receptor 2 (TGFBR2), GLI Family Zinc Finger 3 (GLI3), Solute Carrier Family 16 Member 7 (SLC16A7), Inhibin Subunit Beta A (INHBA), BMP And Activin Membrane-Bound Inhibitor (BAMBI), (APC Down-Regulated 1 APCDD1), G Protein-Coupled Receptor 39 (GPR39) and GATA Binding Protein 4 (GATA4), were selected as candidates for broiler growth based on these results.

\section{Discussion}

Growth trait, especially body weight, is the most important economic trait in the poultry industry. In the current study, we measured eight growth traits in broilers and the genetic parameters of these traits were estimated. We found that the heritability of body weight at different weeks of age was high $\left(h^{2}>0.3\right)$, which is consistent with previous studies, such as Venturini et a1 [13]. found that the heritability of BW5 and BW6 were 0.41 and 0.45 respectively; Kapell et al. $[14,15]$ estimated the heritability of body weight which ranged from 0.326 to 0.399; Mebratie et al. [16] found that the heritability of body weight ranged from 0.31 to 0.37 at different weeks of age in broiler chickens; and Chu et al. [17] found that the heritability of body weight of broilers ranged from 0.28 to 0.33 at different weeks of age. However, the results of some other studies, which found that whereas in our study they ranged from 0.156 to 0.187 [18], were different from the current study. The differences in the results from these studies may be because that the birds used in these studies have different genetic backgrounds and the population sizes were also different. The current study found that the genetic and phenotypic correlations between different growth traits had a large range. Therefore, it is important to pay much more attention when editing the breeding program because when we select one trait the other traits may also have selection responses.

In this study, we used the six multi-locus GWAS methods applied by mrMLM v4.0.2 package to identify SNPs significantly associated with growth traits in broiler chickens. The mixed linear model (MLM) approach has been widely used in GWAS because it can effectively 


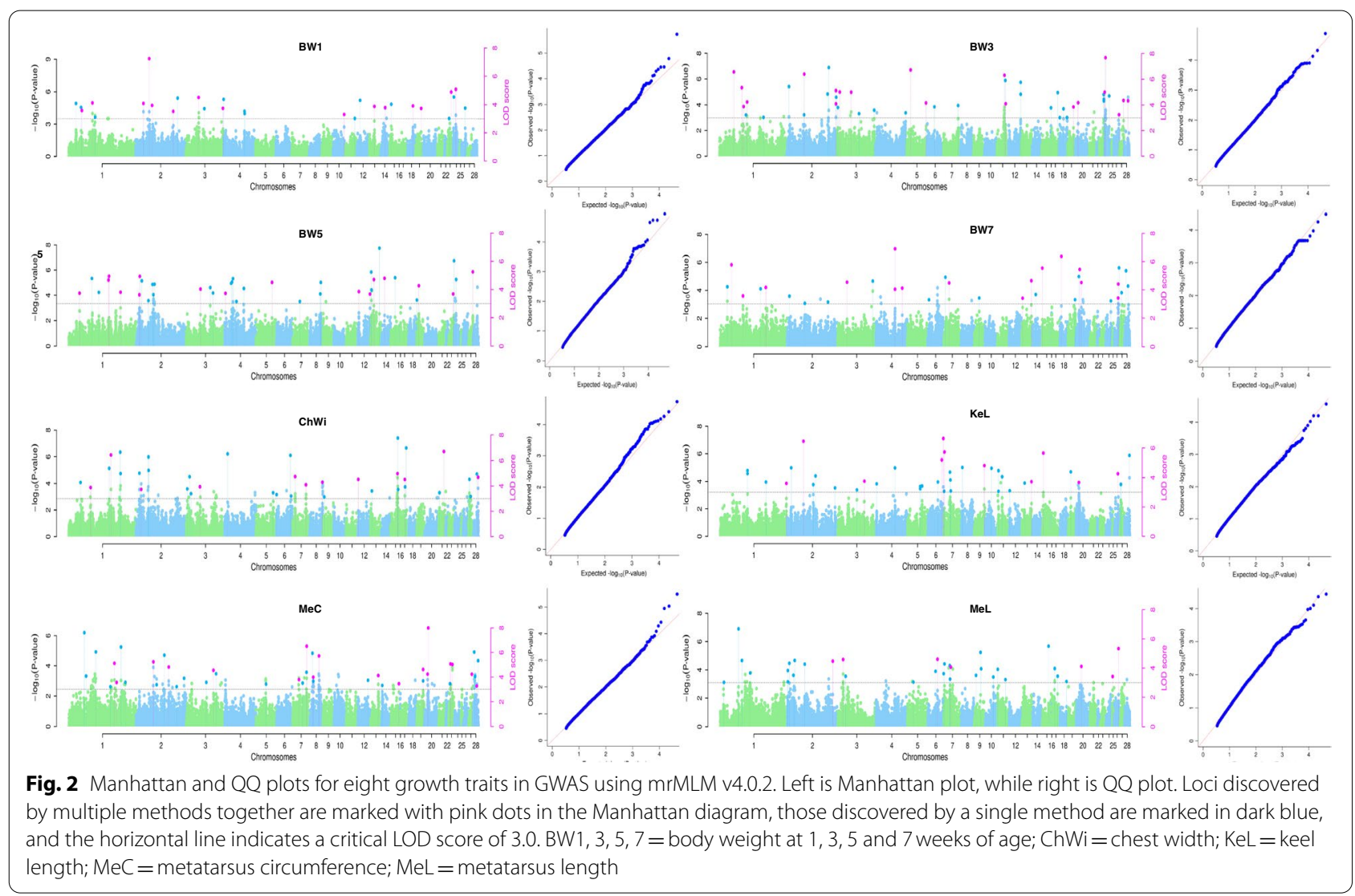

control the false positive rate of SNP detection. Bonferroni correction is a common approach in single-locus GWAS models, but it assumes that markers are independent of each other. Bonferroni correction is too stringent for growth trait data so that many important small effect loci are lost $[19,20]$. In order to solve this problem, Zhang et al. [21] developed an R software mrMLM v4.0.2, including six multi-locus methods (mrMLM [19], FASTmrMLM [21], FASTmrEMMA [20], ISIS EM-BLASSO, pLARmEB, and pKWmEB). Since the number and effects of all potentially associated markers can be determined and estimated simultaneously in the six multi-locus methods, no Bonferroni correction is required. Although the LOD score threshold of 3.0 is set, it can control the false positive rate well and obtain high statistical power.

A total of 113 QTNs with significant effects on growth traits by multiple methods (at least two methods) together in the current study and these QTNs were located on chicken chromosomes $1,2,3,4,6,7,8,12,13$, $15,19,20,23$, and 26. GWAS for body weight was also carried out in some other populations in chicken and these results had some overlaps with the current study. Mebratie et al. [22] carried out the GWAS analysis for body weight and found that QTNs with significant effects on body weight were located on chicken chromosomes 1 ,
$6,8,12,14,23$, and $Z$, which overlapped with the current study. $\mathrm{Xu}$ et al. [23] reported that chromosomes 1 and 4 are the two critical chromosomes influencing growth traits particularly body weight in chickens according to the results of GWAS analysis. Van et al. [24] also identified some QTNs with significant effects on body weight located on chromosomes $1,2,3,4,5,6,7,8,14$, and 26 . The phenotype differences between two alleles of the 26 QTNs with significant effects on growth traits by at least four multi-locus GWAS methods were calculated and the results showed that birds with different alleles have significantly different phenotypes (growth traits) for all 26 QTNs. These results indicated that these QTNs could be used in MAS/GS to select rapid growth in broilers.

There were 184 Refgenes of chicken in $1 \mathrm{Mb}$ region of these 113 QTNs with significant effects on growth traits. The basic function of these 184 genes was extracted from the previous reports and some genes, including ACTA1, IGF2BP1, TAPT1, LDB2, PRKCA, TGFBR2, and GLI3, which were reported to be associated with growth traits in farm animals, were selected as important candidate genes for growth traits in broilers. The results of association study showed that ACTA1 can be used together with others already described to increase the economically important traits in broilers [25]. Three InDels were identified 

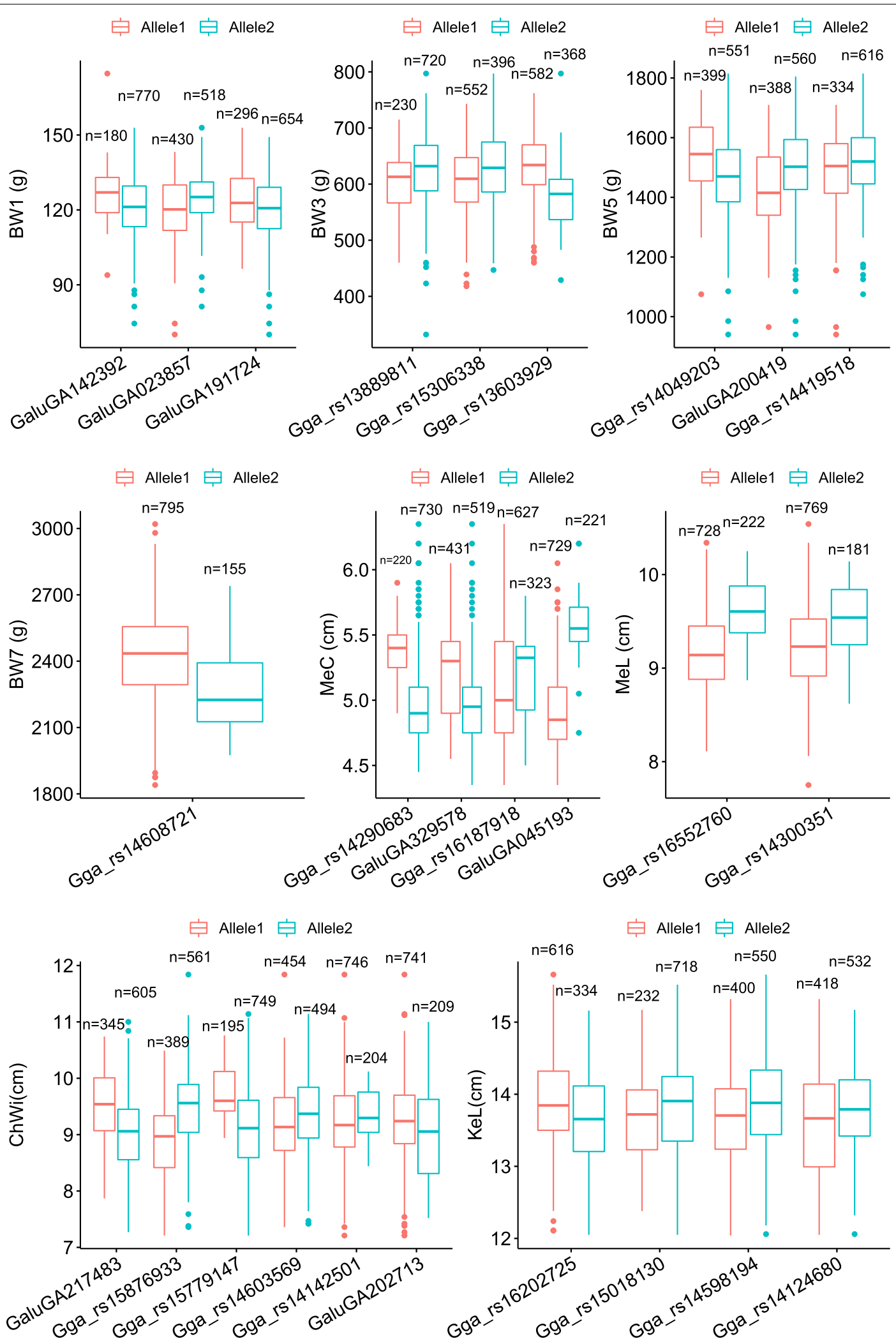

Fig. 3 Phenotypic differences of growth traits in broilers between two alleles of significant QTNs 


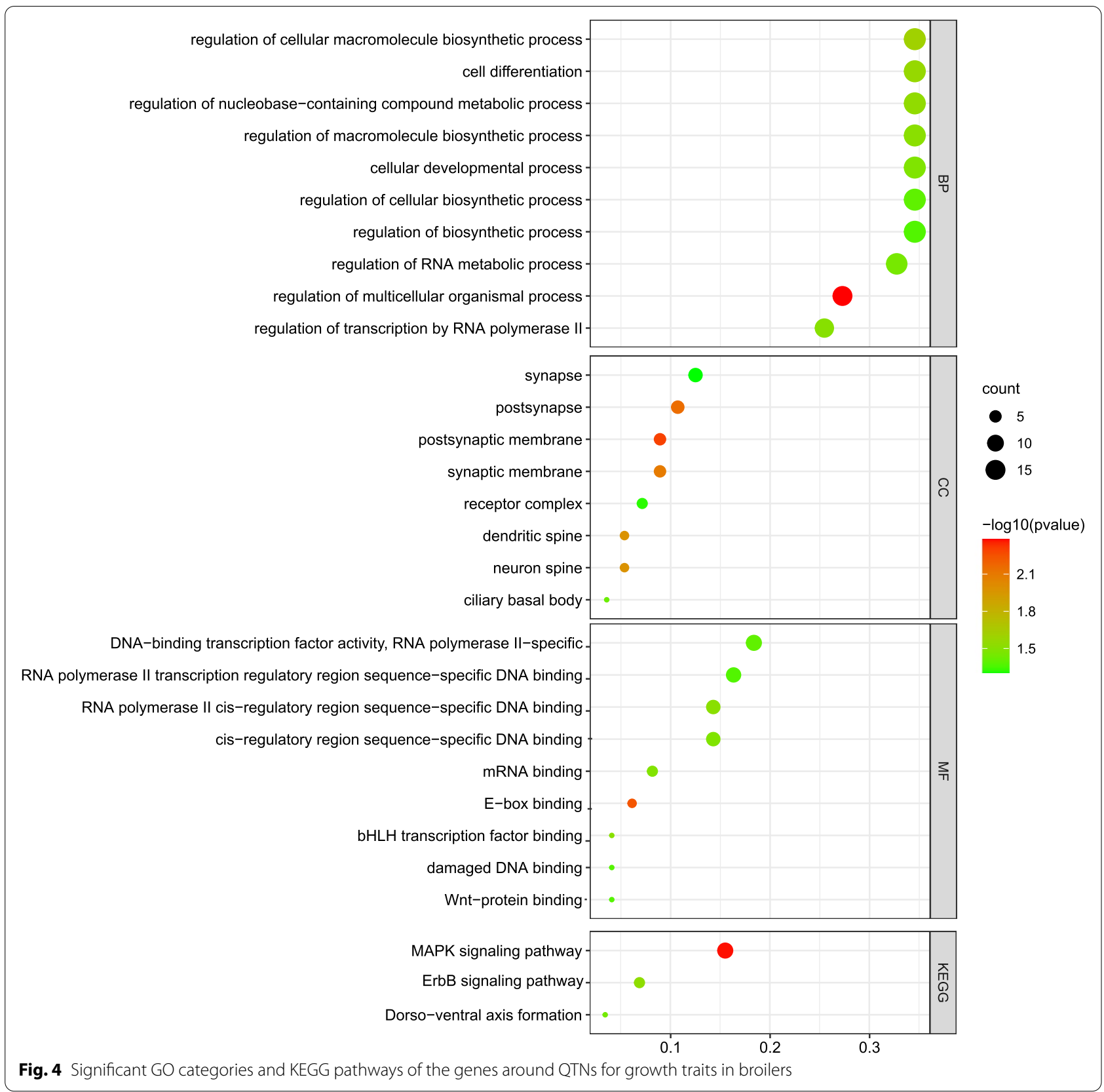

on IGF2BP1 gene that were significantly associated with growth traits in sheep [26]. The polymorphisms of TAPT1 were significantly associated with carcass weight and eviscerated weight in broilers [27]. The 31-bp InDel of the $L D B 2$ gene was significantly correlated with multiple growth and carcass traits in the $\mathrm{F}_{2}$ resource population and affected the expression of $L D B 2$ in muscle tissue [28]. The PRKCA gene was associated with intramuscular fat content in bovine muscle tissue [29]. The TGFBR2 gene plays a negative role in the growth of the scallop, which had a SNP in the $3^{\prime}$ UTR that gives the scallop higher growth performance [30]. The GLI3 gene was important for the development of the mammalian brain and lungs [31]. Furthermore, some other genes, such as SLC16A7, INHBA, BAMBI, APCDD1, GPR39, GATA4 and etc., may also be related to growth traits based on their results on humans and mice [32-38].

\section{Conclusions}

In summary, in this study, we estimated the genetic parameters of eight growth traits in broilers and carried out the GWAS analysis for these growth traits. A total of 113 QTNs with significant effects were detected by multiple methods (at least two methods), and some genes, including ACTA1, IGF2BP1, TAPT1, LDB2, PRKCA, 
TGFBR2, GLI3, SLC16A7, INHBA, BAMBI, APCDD1, GPR39, and GATA4 were identified as important candidate genes for rapid growth in broilers.

\section{Methods \\ Sampling}

Two Northeast Agricultural University broiler lines divergently selected for abdominal fat content (NEAUHLF) were used in this study. A total of 475 male birds (203 and 272 from the lean and fat lines, respectively) from the 11th generation of NEAUHLF were selected to carry out the genome wide association study (GWAS). The same environmental conditions and free access to feed and water were supplied to all these birds. Commercial corn-soybean-based diets which met the requirements of National Research Council were provided. A starter feed (3000kal $\mathrm{ME}=\mathrm{kg}$ and $210 \mathrm{~g}=\mathrm{kg}$ $\mathrm{CP}$ ) was supplied to birds from hatch to 3 weeks of age and a grower diet ( $3100 \mathrm{kal} \mathrm{ME}=\mathrm{kg}$ and $190 \mathrm{~g}=\mathrm{kg} \mathrm{CP}$ ) was supplied to birds from 4weeks of age to slaughter. For reporting of results, we complied with the Animal Research: Reporting In Vivo Experiments guidelines [39]. The birds were weighed at 0 (birth), 1, 3, 5 and 7 weeks of age (BW0, BW1, BW3, BW5 and BW7). At 7 weeks of age, the metatarsus length (MeL), metatarsus circumference (MeC), keel length (KeL) and chest width $(\mathrm{ChWi})$ were measured before slaughter as previously described [40]. Genotypes were obtained using the Illumina chicken $60 \mathrm{~K}$ SNP chip which containing a total of 57,636 SNPs. Quality control was carried out with criteria of a call rate $\geq 95 \%$ and minor allele frequency (MAF) $\geq 0.05$ and a total of 48,824 SNPs were left for GWAS analysis.

\section{Statistical analysis}

The difference of phenotypes between two alleles of every SNPs was calculated using $\mathrm{t}$-test. The genetic parameters, including the heritability of growth traits and the genetic and phenotypic correlations between every two of these growth traits, were estimated using Wombat software [41], with line treated as the fixed effects. Heritability of these traits were estimated using a single-variate model, and the bivariate model was used to calculate the genetic and phenotypic correlations. The genetic model used for parameter estimations is described as follows:

$$
\mathrm{y}=\mathrm{X} \beta+\mathrm{Zu}+\mathrm{e}
$$

in which $y$ is an $\mathrm{n}$-dimensional vector of observed values for the traits, $X$ is an $n \times p$ matrix of the fixed effects, $\beta$ is a $\mathrm{p}$-dimensional vector of the fixed effects, $\mathrm{Z}$ is an $\mathrm{n} \times \mathrm{q}$ matrix of the random effects, $u$ is a q-dimensional vector of the random genetic effects, and e is an n-dimensional vector of the random residual effects.

The random effects $u$ and e were assumed to follow the normal distributions with mean 0 , that is, Expectation $[\mathrm{y}]=\mathrm{X} \beta$. The variances of $u$ and e were assumed to $\operatorname{be} \operatorname{Var}(\mathrm{u})=\mathrm{Ag}$ and
$\operatorname{Var}(\mathrm{e})=\mathrm{Ir}$, respectively, in which $\mathrm{A}$ is the numerator relationship matrix of all animals in the pedigree file, $\mathrm{g}$ is the additive genetic variance for the single-variate and the additive genetic variance-covariance matrix between traits for the bivariate model analysis, I is the identity matrix of order equal to the number of animals with phenotypes, and $r$ is the residual variance for the single-variate and the variance-covariance matrix between residuals on the same animal when performing the bivariate model analysis, where residual covariance equal to 0 [42]. The SNP makers were also used to calculate the genetic correlation between every two traits, which means that the individual correlation matrix (A) from pedigree information was replaced by genomic information ( $G$ matrix). And the results from $\mathrm{G}$ matrix were described in Fig. 1.

The Genome-wide Rapid Association using multi-locus GWAS methods in the mrMLM v4.0.2 package, [21] was used to carry out GWAS. This mixed model contained Line (two broiler lines) and BW0 as covariates. Default values were used for all parameters.

\section{Gene detection and functional annotation}

SNPs with significant effects on growth traits were detected by using GWAS method as above and the genes located in $1 \mathrm{Mb}$ region of these significant SNPs were retrieved from UCSC (https://genome.ucsc.edu/) (Galgal6). The Gene Ontology (GO) terms and Kyoto Encyclopedia of Genes and Genomes (KEGG) pathway analysis were carried out using DAVID bioinformatics resources 6.8 (http://david.abcc.ncifc rf.gov/summary.jsp) for these genes [43-46]. $P$-value $<0.05$ was used as the statistical significance level.

\section{Abbreviations}

MAS: Marker assist selection; GS: Genomic selection; GWAS: Genome-wide association studies; SNP: Single nucleotide polymorphism; QTN: Quantitative trait nucleotide; NEAUHLF: Northeast Agricultural University broiler lines divergently selected for abdominal fat conten; AFP: Abdominal fat percentage; BW: Body weight; MeL: Metatarsus length; MeC: Metatarsus circumference; KeL: Keel length; ChWi: Chest width; MAF: Minor allele frequency; MLM: Mixed linear model; GO: Gene Ontology; KEGG: Kyoto Encyclopedia of Genes and Genomes.

\section{Supplementary Information}

The online version contains supplementary material available at https://doi. org/10.1186/s12863-021-01017-7.

Additional file 1: Table S1. Significant QTNs for eight different growth traits in broilers co-detected at least two multi-locus GWAS methods. ${ }^{1}$ QTNs in bold font are pleiotropic QTNs which were detected associate with multiple traits. ${ }^{2}$ Chicken Refgenes in bold font indicates multiple occurrences of the gene.

\section{Acknowledgments}

The authors would like to acknowledge the members of the Poultry Breeding Group of the College of Animal Science and Technology at the Northeast Agricultural University for managing the birds and collecting the data, and Haihe Gao for his help during the revision of the article. 


\section{Authors' contributions}

DD and LS collected samples and drafted the manuscript. JZ participated in the experiments. ZC, PL, YL, FX and HG contributed the reagents, materials, and analysis tools. HL participated in the design of the study and contributed to the analysis of the data. $\mathrm{HZ}$ designed this study and was a major contributor in writing the manuscript. All authors read and approved the final manuscript.

\section{Funding}

This research was supported by the National Natural Science Foundation of China (No. 31972549), China Agriculture Research System of MOF and MARA (No. CARS-41), Heilongjiang Postdoctoral Financial Assistance (No. LBH-Q20006), and "Academic Backbone" Project of Northeast Agricultural University (No. 17XG18). These funding agencies played no role in the design of the study, data collection, analysis, and interpretation, or in writing the manuscript.

\section{Availability of data and materials}

The data sets supporting the results of this article are included within the article and its additional files. The chicken $60 \mathrm{k}$ SNP data presented in this paper have been deposited into Gene Expression Omnibus (http://www.ncbi.nlm. nih.gov/geo/) with the identifier GSE58551.

\section{Declarations}

\section{Ethics approval and consent to participate}

All animal work was conducted according to the guidelines for the Care and Use of Experimental Animals established by the Ministry of Science and Technology of the People's Republic of China (approval number: 2006-398) and approved by the Laboratory Animal Management Committee of Northeast Agricultural University.

\section{Consent for publication}

Not applicable.

\section{Competing interests}

The authors declare that they have no competing interests.

\section{Author details}

${ }^{1}$ Key Laboratory of Chicken Genetics and Breeding, Ministry of Agriculture and Rural Affairs; Key Laboratory of Animal Genetics, Breeding and Reproduction, Education Department of Heilongjiang Province; College of Animal Science and Technology, Northeast Agricultural University, Harbin 150030, P. R. China. ${ }^{2}$ Fujian Sunnzer Biotechnology Development Co., Ltd, Nanping 354100, P. R. China.

\section{Received: 18 June 2021 Accepted: 30 November 2021}

Published online: 03 January 2022

\section{References}

1. Liang B, Ding H, Huang L, Luo H, Zhu X. GWAS in cancer: progress and challenges. Mol Gen Genomics. 2020;295(3):537-61. https://doi.org/10. 1007/s00438-020-01647-z

2. Tavares V, Pinto R, Assis J, Pereira D, Medeiros R. Venous thromboembolism GWAS reported genetic makeup and the hallmarks of cancer: Linkage to ovarian tumour behaviour. Biochim Biophys Acta Re Cancer. 2020;1873(1):188331. https://doi.org/10.1016/j. bbcan.2019.188331.

3. Bergamaschi M, Maltecca C, Fix J, Schwab C, Tiezzi F. Genome-wide association study for carcass quality traits and growth in purebred and crossbred pigs1. J Anim Sci. 2020;98(1):skz360.

4. He S, Zhang Z, Sun Y, Ren T, Li W, Zhou X, et al. Genome-wide association study shows that microtia in Altay sheep is caused by a 76 bp duplication of HMX1. Anim Genet. 2020;51(1):132-6.

5. Zaalberg RM, Janss L, Buitenhuis AJ. Genome-wide association study on Fourier transform infrared milk spectra for two Danish dairy cattle breeds. BMC Genet. 2020;21(1):9. https://doi.org/10.1186/s12863-020-0810-4.
6. Xie L, Luo C, Zhang C, Zhang R, Tang J, Nie Q, et al. Genome-wide association study identified a narrow chromosome 1 region associated with chicken growth traits. PLoS One. 2012;7(2):e30910. https://doi.org/10. 1371/journal.pone.0030910.

7. Zhang GX, Fan QC, Wang JY, Zhang T, Xue Q, Shi HQ. Genome-wide association study on reproductive traits in Jinghai Yellow Chicken. Anim Reprod Sci. 2015;163:30-4. https://doi.org/10.1016/j.anireprosci.2015.09. 011.

8. Moreira G, Boschiero C, Cesar A, Reecy JM, Godoy TF, Pértille F, et al. Integration of genome wide association studies and whole genome sequencing provides novel insights into fat deposition in chicken. Sci Rep. 2018;8(1):16222. https://doi.org/10.1038/s41598-018-34364-0.

9. Liu Z, Yang N, Yan Y, Li G, Liu A, Wu G, et al. Genome-wide association analysis of egg production performance in chickens across the whole laying period. BMC Genet. 2019;20(1):67. https://doi.org/10.1186/ s12863-019-0771-7.

10. Guo L, Sun B, Shang Z, Leng L, Wang Y, Wang N, et al. Comparison of adipose tissue cellularity in chicken lines divergently selected for fatness. Poult Sci. 2011;90(9):2024-34.

11. Zhang H, Na W, Zhang HL, Wang N, Du ZQ, Wang SZ, et al. TCF21 is related to testis growth and development in broiler chickens. Genet Sel Evol. 2017:49(1):25. https://doi.org/10.1186/s12711-017-0299-0.

12. Zhang H, Shen L, Li Y, Xu Z, Zhang X, Yu J, et al. Genome-wide association study for plasma very low-density lipoprotein concentration in chicken. J Anim Breed Genet. 2019;136(5):351-61. https://doi.org/10.1111/jbg. 12397.

13. Venturini GC, Stafuzza NB, Cardoso DF, Baldi F, Ledur MC, Peixoto JO, et al. Association between ACTA1 candidate gene and performance, organs and carcass traits in broilers. Poult Sci. 2016;95(5):1221. https://doi.org/10. 3382/ps/pew134.

14. Kapell DN, Hill WG, Neeteson AM, McAdam J, Koerhuis AN, Avendaño S. Genetic parameters of foot-pad dermatitis and body weight in purebred broiler lines in 2 contrasting environments. Poult Sci. 2012;91(3):565-74.

15. Kapell DN, Hill WG, Neeteson AM, McAdam J, Koerhuis AN, Avendaño S. Twenty-five years of selection for improved leg health in purebred broiler lines and underlying genetic parameters. Poult Sci. 2012;91(12):3032-43. https://doi.org/10.3382/ps.2012-02578.

16. Mebratie W, Madsen $\mathrm{P}$, Hawken R, Romé H, Marois D, Henshall J, et al. Genetic parameters for body weight and different definitions of residual feed intake in broiler chickens. Genet Sel Evol. 2019;51(1):53. https://doi. org/10.1186/s12711-019-0494-2.

17. Chu TT, Madsen P, Norberg E, Wang L, Marois D, Henshall J, et al. Genetic analysis on body weight at different ages in broiler chicken raised in commercial environment. J Anim Breed Genet. 2020;137(2):245-59. https://doi.org/10.1111/jbg.12448.

18. Momen M, Mehrgardi AA, Sheikhy A, Esmailizadeh A, Fozi MA, Kranis A, et al. A predictive assessment of genetic correlations between traits in chickens using markers. Genet Sel Evol. 2017;49(1):16. https://doi.org/10. 1186/s12711-017-0290-9.

19. Wang SB, Feng JY, Ren WL, Huang B, Zhou L, Wen YJ, et al. Improving power and accuracy of genome-wide association studies via a multilocus mixed linear model methodology. Sci Rep. 2016;6:19444. https:// doi.org/10.1038/srep19444.

20. Wen YJ, Zhang H, Ni YL, Huang B, Zhang J, Feng JY, et al. Methodological implementation of mixed linear models in multi-locus genome-wide association studies. Brief Bioinform. 2018;19(4):700-12. https://doi.org/10. 1093/bib/bbw145.

21. Zhang YW, Tamba CL, Wen YJ, Li P, Ren WL, Ni YL, et al. mrMLM v4.0.2: An R Platform for Multi-locus Genome-wide Association Studies. Genomics Proteomics Bioinform. 2020;18(4):481-7. https://doi.org/10.1016/j.gpb. 2020.06.006.

22. Mebratie W, Reyer H, Wimmers K, Bovenhuis H, Jensen J. Genome wide association study of body weight and feed efficiency traits in a commercial broiler chicken population, a re-visitation. Sci Rep. 2019;9(1):922. https://doi.org/10.1038/s41598-018-37216-z.

23. Xu Z, Nie Q, Zhang X. Overview of genomic insights into chicken growth traits based on genome-wide association study and microRNA regulation. Curr Genomics. 2013;14(2):137-46. https://doi.org/10.2174/13892 02911314020006.

24. Van Goor A, Bolek KJ, Ashwell CM, Persia ME, Rothschild MF, Schmidt CJ, et al. Identification of quantitative trait loci for body temperature, body 
weight, breast yield, and digestibility in an advanced intercross line of chickens under heat stress. Genet Sel Evol. 2015;47:96. https://doi.org/10. 1186/s12711-015-0176-7.

25. Venturini GC, Stafuzza NB, Cardoso DF, Baldi F, Ledur MC, Peixoto JO, et al. Association between ACTA1 candidate gene and performance, organs and carcass traits in broilers. Poult Sci. 2015;94(12):2863-9. https://doi. org/10.3382/ps/pev285.

26. Liu H, Xu H, Lan X, Cao X, Pan C. The InDel variants of sheep IGF2BP1 gene are associated with growth traits. Anim Biotechnol. 2021;1-9. https://doi. org/10.1080/10495398.2021.1942029.

27. Liu R, Sun Y, Zhao G, Wang F, Wu D, Zheng M, et al. Genome-wide association study identifies Loci and candidate genes for body composition and meat quality traits in Beijing-You chickens. PLoS One. 2013;8(4):e61172. https://doi.org/10.1371/journal.pone.0061172.

28. Wei C, Hou D, Feng Y, Li T, Jing Z, Li W, et al. Molecular characterization and a duplicated 31-bp indel within the LDB2 gene and its associations with production performance in chickens. Gene. 2020;761:145046. https://doi.org/10.1016/j.gene.2020.145046.

29. Wang H, Zhong J, Zhang C, Chai Z, Cao H, Wang J, et al. The whole-transcriptome landscape of muscle and adipose tissues reveals the ceRNA regulation network related to intramuscular fat deposition in yak. BMC Genomics. 2020;21(1):347. https://doi.org/10.1186/s12864-020-6757-z.

30. Guo H, Bao Z, Li J, Lian S, Wang S, He Y, et al. Molecular characterization of TGF-beta type I receptor gene (Tgfbr 1 ) in Chlamys farreri, and the association of allelic variants with growth traits. PLoS One. 2012;7(11):e51005. https://doi.org/10.1371/journal.pone.0051005.

31. Matissek SJ, Elsawa SF. GLI3: a mediator of genetic diseases, development and cancer. Cell Commun Signal. 2020;18(1):54. https://doi.org/10.1186/ s12964-020-00540-x.

32. Abousoliman I, Reyer H, Oster M, Murani E, Mohamed I, Wimmers K. Genome-Wide Analysis for Early Growth-Related Traits of the Locally Adapted Egyptian Barki Sheep. Genes. 2021;12(8):1243. https://doi.org/ 10.3390/genes12081243.

33. Yu DY, Wu RZ, Zhao Y, Nie ZH, Wei L, Wang TY, et al. Polymorphisms of four candidate genes and their correlations with growth traits in blue fox (Alopex lagopus). Gene. 2019;717:143987. https://doi.org/10.1016/j.gene. 2019.143987.

34. Yang X, Ning Y, Mei C, Zhang W, Sun J, Wang S, et al. The role of BAMBI in regulating adipogenesis and myogenesis and the association between its polymorphisms and growth traits in cattle. Mol Biol Rep. 2020;47(8):5963-74. https://doi.org/10.1007/s11033-020-05670-6.

35. Li S, Chen W, Zheng X, Liu Z, Yang G, Hu X, et al. Comparative investigation of coarse and fine wool sheep skin indicates the early regulators for skin and wool diversity. Gene. 2020;758:144968. https://doi.org/10.1016/j. gene.2020.144968.

36. Allouche-Fitoussi D, Breitbart H. The Role of Zinc in Male Fertility. Int J Mol Sci. 2020;21(20):7796. https://doi.org/10.3390/ijms21207796.

37. Jiang Q, Mei L, Zou Y, Ding Q, Cannon RD, Chen H, et al. Genetic Polymorphisms in FGFR2 Underlie Skeletal Malocclusion. J Dent Res. 2019;98(12):1340-7. https://doi.org/10.1177/0022034519872951.

38. Hu Y, Xu H, Li Z, Zheng $X$, Jia $X$, Nie $Q$, et al. Comparison of the genomewide DNA methylation profiles between fast-growing and slow-growing broilers. PLoS One. 2013;8(2):e56411. https://doi.org/10.1371/journal. pone.0056411.

39. Percie du Sert N, et al. The ARRIVE guidelines 2.0: Updated guidelines for reporting animal research. PLoS Biol. 2020;18(7):e3000410.

40. Zhang F, Deng HW. Correcting for cryptic relatedness in populationbased association studies of continuous traits. Hum Hered. 2010;69(1):2833. https://doi.org/10.1159/000243151.

41. Meyer K. WOMBAT: a tool for mixed model analyses in quantitative genetics by restricted maximum likelihood (REML). J Zhejiang Univ-SC B. 2007;8(11):815-21. https://doi.org/10.1631/jzus.2007.B0815.

42. Buchanan JW, Reecy JM, Garrick DJ, Duan Q, Beitz DC, Mateescu RG. Genetic parameters and genetic correlations among triacylglycerol and phospholipid fractions in Angus cattle. J Anim Sci. 2015;93(2):522-8.

43. Ashburner M, Ball CA, Blake JA, Botstein D, Butler H, Cherry JM, et al. Gene ontology: tool for the unification of biology. Nat Genet. 2000;25(1):25-9. https://doi.org/10.1038/75556 Gene Ontology Consortium.

44. Gene Ontology Consortium. The Gene Ontology resource: enriching a GOld mine. Nucleic Acids Res. 2021;49(D1):D325-34. https://doi.org/10. 1093/nar/gkaa1113.
45. Kanehisa M, Goto S. KEGG: kyoto encyclopedia of genes and genomes. Nucleic Acids Res. 2000;28(1):27-30. https://doi.org/10.1093/nar/28.1.27.

46. Kanehisa M, Furumichi M, Sato Y, Ishiguro-Watanabe M, Tanabe M. KEGG: integrating viruses and cellular organisms. Nucleic Acids Res. 2021:49(D1):D545-51. https://doi.org/10.1093/nar/gkaa970.

\section{Publisher's Note}

Springer Nature remains neutral with regard to jurisdictional claims in published maps and institutional affiliations.
Ready to submit your research? Choose BMC and benefit from:

- fast, convenient online submission

- thorough peer review by experienced researchers in your field

- rapid publication on acceptance

- support for research data, including large and complex data types

- gold Open Access which fosters wider collaboration and increased citations

- maximum visibility for your research: over $100 \mathrm{M}$ website views per year

At BMC, research is always in progress.

Learn more biomedcentral.com/submissions 